\title{
Sublethal damage to Acanthaster planci as an index of predation pressure
}

\author{
H. I. McCallum, R. Endean, Ann M. Cameron
}

Department of Zoology, University of Queensland, St. Lucia, 4067 Australia

\begin{abstract}
Almost $40 \%$ of adult crown-of-thorns starfish Acanthaster planci examined at Holbourne Island, Great Barrier Reef, showed evidence of predator attack, with arms either missing or regenerating. The identity of the injury-causing agents is unknown. At the time of the survey, Holbourne Island was carrying an active starfish outbreak consisting of a high density front population, made up of mostly large individuals, and lower density populations of smaller individuals away from the front. Starfish were surveyed on 13 transects chosen to cover as wide a range of local starfish densities as possible. There was significant heterogeneity between transects in the proportion of injured starfish. This could be explained statistically either as being inversely related to starfish density on the transect or inversely related to mean starfish diameter. As mean diameter and density were strongly positively correlated, these effects were difficult to disentangle. These data are consistent with a Type II functional response on the part of the predators. This indicates that the impact of predation on $A$. planci populations is likely to be reduced at very high population densities, but may be large indeed in "normal' low density populations
\end{abstract}

\section{INTRODUCTION}

The hard coral cover of a substantial proportion of the reefs of the Great Barrier Reef system has been damaged by population outbreaks of the crown-ofthorns starfish Acanthaster planci (L.) (Endean \& Cameron 1985, Moran 1986), resulting in a 'major management problem in some areas of the Great Barrier Reef' (Crown of Thorns Starfish Advisory Committee 1985). A range of hypotheses has been advanced to account for the population outbreaks leading to this damage (see reviews by Potts 1982 and Moran 1986).

One such hypothesis, first advanced by Endean (1969), is that outbreaks have occurred as a result of human removal of predators of the starfish. This suggestion, unfortunately, is difficult to test directly: simple predator exclusion experiments (e.g. Paine 1966) are not feasible at the scale of entire reefs and predation in any situation is always a rare event (considered per head of prey) and unlikely to be often observed in the field particularly if the prey is itself normally rare.

Determination of the nature of the factors regulating a population is rarely straightforward. As Harper (1977. p. 510) has pointed out the prime cause of death in a population need not be a regulator...' and 'the regulator need not be the most obvious cause of death'.

In common with many echinoderms (e.g. Sides 1987), the crown-of-thorns starfish is capable of regenerating substantial proportions of its body following attack by a predator and evidence of the attack remains visible for a considerable length of time (Owens 1971). Known predators of large juvenile and adult Acanthaster planci are listed by Endean (1973) and Moran (1986) and include 5 teleost species (Cheilinus undulatus, Arothron hispidus, Balistoides viridescens, Pseudobalistes flavimarginatus and Promicrops lanceolatus), 2 gastropod species (Charonia tritonis and Bursa rubeta), 3 crustacean species (Hymenocera picta, Neaxius glyptocerus and Promidiopsis dormia) and a polychaete (Pherecardia striata). Other large teleost and elasmobranch species may also consume substantial parts of the body of adult or large juvenile $A$. planci (Moran 1986, Endean \& Cameron in press).

A possible approach to the problem of measuring the rate of predation is to use the number of individuals with missing or regenerating arms as an index of the rate of predation on a given starfish population. This paper investigates variability in predation intensity, as measured by starfish damage rate, at a local scale on a single reef. 


\section{MATERIALS AND METHODS}

Study site. Holbourne Island $\left(19^{\circ} 43^{\circ} \mathrm{S}, 148^{\circ} 21^{\prime} \mathrm{E}\right)$ is a continental island in the central portion of the Great Barrier Reef (Fig. 1). It has a broad fringing reef, 2 to $3 \mathrm{~m}$ deep at low tide, on the southwestern side, and a narrower fringing reef on the opposite side. As it is within $30 \mathrm{~km}$ of the town of Bowen (population 7700), it is subject to significant commercial and recreational fishing pressure.

Survey methods. Thirteen $100 \mathrm{~m}$ transects were laid out on the reef flat to the south of the island (see locations in Fig. 1), and the area $5 \mathrm{~m}$ on either side of the transect line was exhaustively searched for Acanthaster planciby divers using SCUBA. The locations of transects were chosen to provide as wide a coverage of the range of local starfish population densities at Holbourne Island as possible. Transects 1 to 6 were examined in February, 7 to 11 in April, and 12 \& 13 in May 1987.

The location of each starfish found was recorded, together with its greatest diameter (measured from arm tip to arm tip), the total number of arms, the number of missing arms (defined as those with no evidence of regeneration) and the number of regenerating arms. Arms were scored as regenerating if they were obviously shorter than arms on either side of the injury. (Although arm number in Acanthaster planci is variable, further arms are not added after the starfish reaches a size of $\mathrm{ca} 15 \mathrm{~mm}$ in diameter; Yamaguchi 1973). Each starfish was examined for signs of pathogen-induced tissue disintegration. On the field trips in April and May, information was obtained on whether damaged arms were adjacent in addition to the other variables. In a small number of cases, starfish located were unable to be retrieved and data on size, number of arms and injuries could not be recorded. These individuals are included in calculations of starfish density, but could not be included in the other calculations.

\section{RESULTS}

\section{Starfish abundance}

At the time of the initial field trip in February 1987 , many starfish were present on the Holbourne Island reef, with a total population estimated as being in excess of 10000 individuals (Great Barrier Reef Marine Park Authority unpubl.). The starfish were clustered in a 'front', running across the reef flat in the approximate location shown in Fig. 1

As transect locations were selected primarily to provide coverage of a wide range of local starfish population densities, rather than being selected at random, these data cannot validly be used to investigate changes in starfish numbers over the period of the study. It was apparent, however, that by April most of the coral in the primary study area had been eaten, and the front was no longer as clearly defined as previously.

\section{Injuries to starfish}

A total of 276 starfish were present in the $11439 \mathrm{~m}^{2}$ surveyed in the 13 transects. Information on predator damage was available for all but 13 starfish. Overall nearly $40 \%$ of starfish showed some evidence of predator damage (Table 1). No starfish showed evidence of necrotic lesions in the aboral disc of the kind reported by Zann et al. (1987) to be characteristic of pathogen damage. Of the 105 starfish located with evidence of damage, only 8 had arms classified as 'missing' (no evidence of regeneration). The frequency distribution of the number of arms injured (missing or regenerating) is shown in Fig. 2. The injuries were distributed in an aggregated fashion amongst starfish.

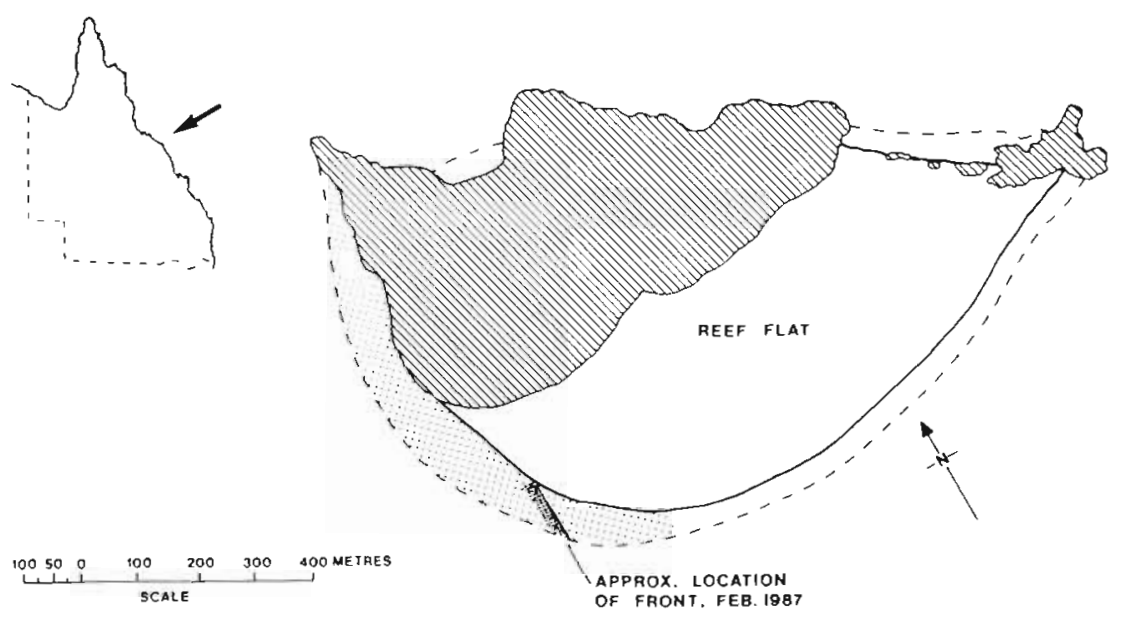

Fig. 1. Holbourne Island. Location of the island is shown arrowed on the inset map of Queensland. Hatching indicates the land area of the island, dashed line marks the edge of the fringing reef. Transects were laid within the stippled area 


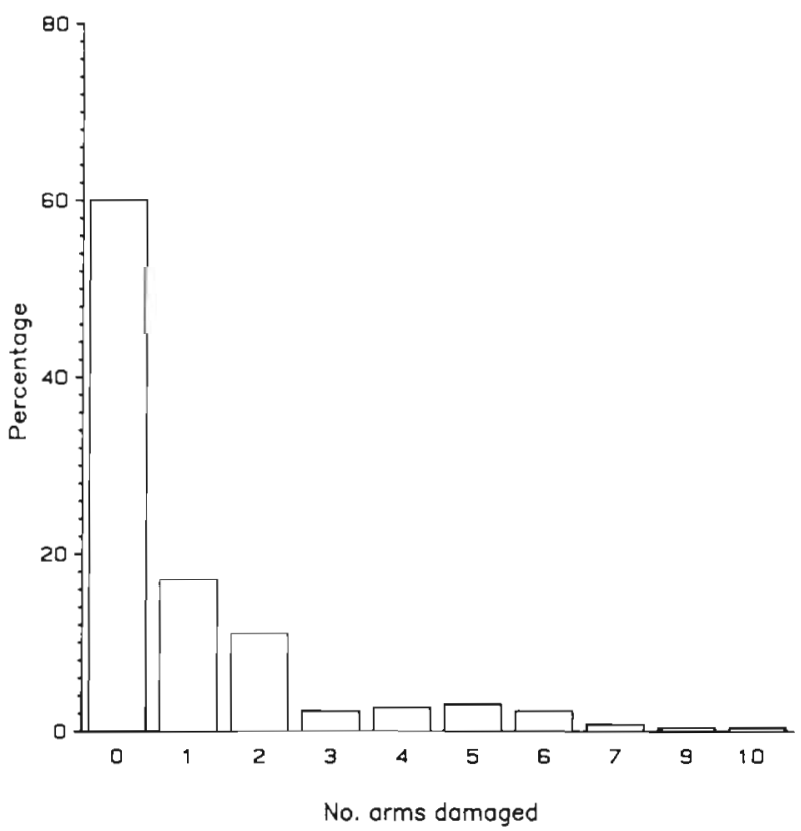

Fig. 2. Acanthaster planci. Frequency distribution of the number of injured arms on all starfish surveyed at Holbourne Island. Injuries were not distributed randomly amongst starfish, but were aggregated. $\left(S^{2 / \bar{x}}=2.99, \chi^{2}=783,262 \mathrm{df}, \mathrm{p}<0.0001\right)$

In cases where individual starfish had more than one injured arm, the damaged arms were frequently adjacent, suggesting that several arms were injured in the same attack or that initial injury facilitates further attacks in the same area as the previous injuries. Fig. 3 shows the frequency distribution of the number of injuries amongst starfish with some evidence of predator damage recorded on the second and third field trips, together with the number of groups of injuries.
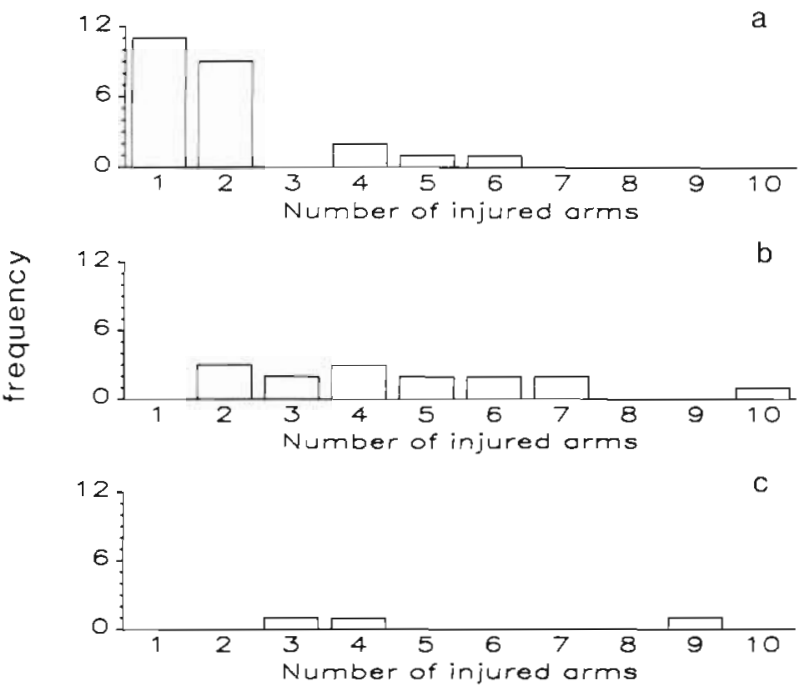

Fig. 3. Acanthaster planci. Frequency distributions of the number of injured arms on all starfish surveyed during the second and third field trips which showed evidence of injury. (a) Injured arms in 1 contiguous group. (b) Injured arms in 2 groups. (c) Injured arms in 3 groups

Although independent attacks would have a certain probability of occurring on adjacent arms, it is clear that the damaged arms are clustered in groups around the discs of the starfish, with as many as 6 injured arms forming a single group.

Starfish ranged in size from ca 20 to $75 \mathrm{~cm}$, covering the entire size range of 'adult' starfish as reported by Moran (1986). Arm number varied from 10 to 20 (median 16). When starfish were grouped into $5 \mathrm{~cm}$ size classes (Fig. 4), injuries were recorded in all size classes with the exception of that containing the single largest individual. There is a strong indication of bimodality in
Fig. 4. Acanthaster planci. Size frequency distribution of injured and uninjured starfish on all transects. Open bars: uninjured starfish; hatched bars: injured starfish. Starfish are grouped into $5 \mathrm{~cm}$ size classes with midpoints as shown

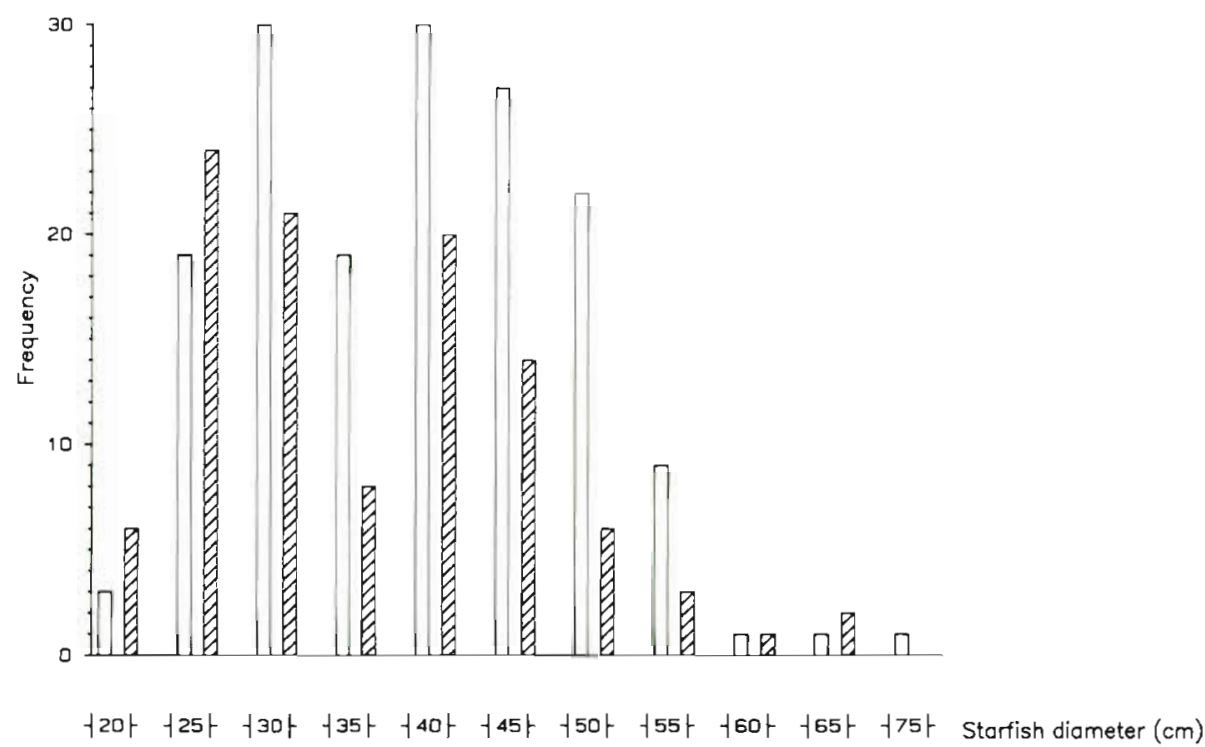


the size frequency distributions of both injured and intact starfish. It also appears that injury levels are greater amongst small individuals than in the larger size classes. This possibility is explored more fully in the analysis that follows.

Table 1 summarizes the results of the transect surveys. A generalized linear modelling approach was

Table 1. Acanthaster planci. Details of numbers, sizes, densities and proportion injured of starfish found on each of 13 transects surveyed at Holbourne Island. Area of each transect was $1000 \mathrm{~m}^{2}$, except for those marked ${ }^{\cdot}$ and ${ }^{+}$, where $164 \mathrm{~m}^{2}$ and $275 \mathrm{~m}^{2}$ were surveyed respectively. Proportion of injured starfish varied significantly between transects $\left(x^{2}=27.79\right.$, $12 \mathrm{df}, \mathrm{p}<0.01$ ). Starfish diameter also varied significantly (1. way ANOVA; $F=27.15 ; \mathrm{d} f=12,254 ; \mathrm{p}<0.0001)$

\begin{tabular}{|lrrrr|}
\hline Month & $\begin{array}{r}\text { No. of } \\
\text { starfish }\end{array}$ & $\begin{array}{c}\text { Mean } \\
\text { diameter } \\
(\mathrm{cm})\end{array}$ & $\begin{array}{c}\text { Starfish } \\
\text { density } \\
\left(\mathrm{m}^{-2}\right)\end{array}$ & $\begin{array}{c}\text { Proportion } \\
\text { injured }\end{array}$ \\
\hline Feb & 76 & 44.7 & $0.512^{*}$ & 0.329 \\
Feb & 29 & 28.1 & 0.031 & 0.414 \\
Feb & 65 & 44.0 & 0.066 & 0.308 \\
Feb & 4 & 36.3 & 0.004 & 1.00 \\
Feb & 2 & 32.5 & 0.002 & 1.00 \\
Feb & 1 & 28.0 & 0.001 & 0.00 \\
Apr & 13 & 25.7 & 0.013 & 0.615 \\
Apr & 7 & 29.7 & 0.007 & 0.429 \\
Apr & 13 & 28.8 & 0.013 & 0.615 \\
Apr & 7 & 29.7 & 0.007 & 0.857 \\
Apr & 7 & 21.1 & 0.007 & 0.286 \\
May & 30 & 33.2 & $0.109^{+}$ & 0.367 \\
May & 10 & 35.4 & 0.011 & 0.400 \\
Mean & & & & 0.398 \\
\hline
\end{tabular}

taken to analyse these data, using a binomial error distribution and logistic link function (McCullagh \& Nelder 1983). This method is a generalization of the techniques of analysis of variance and covariance which deals with dichotomous response data. It is a more powerful method than the approach using arcsine transformations that is frequently used.

There is strong evidence that the proportion of injured starfish varied between transects. Starfish diameter also varied significantly between transects. Three possible explanatory factors were considered for the differences in the proportion of injured starfish between transects: the mean diameter of starfish on the transect, the starfish density on the transect, and the date of the survey. The proportion of injured starfish is shown in relation to the first two of these factors in Figs. 5 and 6 . Any of the 3 factors, considered alone, explains a significant amount of the variation in the proportion of injured starfish (Table 2). The insignificant ( $p>0.05$ ) residual deviance after $\log$ density is fitted indicates that this factor is sufficient to explain the variability in injury rates between transects. Both the survey date

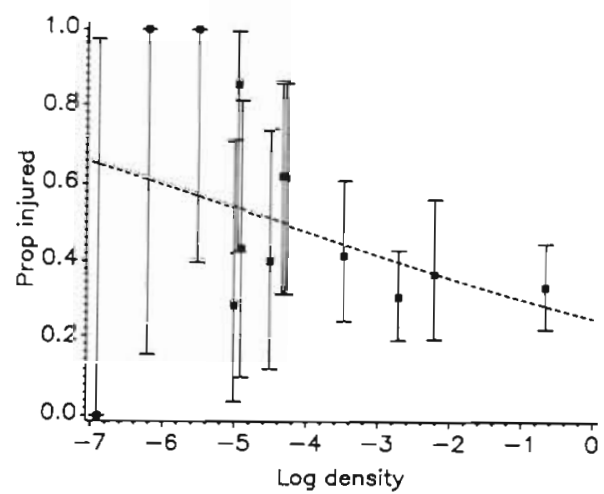

Fig. 5. Acanthaster planci. Relationship between the natural logarithm of starfish density on transects and the proportion of starfish present injured. $95 \%$ confidence intervals for the proportion injured are shown. The dashed line is the best-fit logistic relation between log density and proportion injured: $p=\exp (a+b x) /(1+\exp (a+b x))$, where $p$ is the proportion injured, $x$ is the $\log$ density and $a$ and $b$ are parameters estimated as -1.081 and -0.2464 respectively. Where 2 or more transects have the same starfish density, results have been slightly offset to avoid superimposition

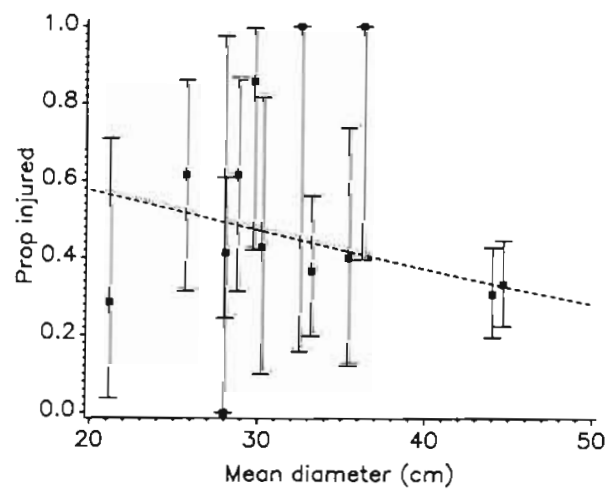

Fig. 6. Acanthaster planci. Relationship between mean starfish diameter on transects and proportion of injured starfish. $95 \%$ confidence intervals for the proportion of injured starfish are shown. The dashed line is the best fit logistic relation between mean diameter and proportion injured: $p=\exp$ $(a+b d) /(1+\exp (a+b d))$ where $p$ is the proportion injured, $d$ is the mean diameter and $a$ and $b$ are parameters estimated as 1.126 and -0.04121 respectively. As in Fig. 5, results have been slightly offset where necessary to avoid superimposition

and mean diameter, however, leave a significant residual deviance.

Unfortunately the factors are confounded, large starfish being found mostly in high densities and on the first of the field trips. Fig. 7 shows the strong positive association between the mean starfish diameter on transects and the log of local starfish density. This association hampers the unequivocal attribution of the observed differences in the proportion of injured starfish to any one of the factors considered. Each factor, considered alone, has significant explanatory power, 
Table 2. Results of fitting single factors in a generalized linear model for the proportion of injured starfish on transects. The deviance has an approximately chi-squared distribution. For each factor, a significant change in deviance from the null model means that the factor, considered alone, explains a significant amount of the variation in the proportion of injured starfish. An insignificant residual deviance means that the factor alone is an adequate predictor of variation in the proportion of starfish injured. Parameter values for the effects of log density and mean diameter are given in the legends of Figs. 5 and 6 respectively. For survey date, estimates of the difference from the February survey in the log odds of injury to starfish are: April, 0.893, SE $=$ 0.334; May, $0.082, \mathrm{SE}=0.362$, indicating that the main contributor to the significance of this factor is that a higher proportion of starfish were found injured in April than in either February or May. Log density fitted after either date or diameter was significant at approximately the $\mathrm{p}=0.1$ level $\left(\chi^{2}=2.75\right.$ and 2.68 respectively, $\left.1 \mathrm{df}\right)$. Changes in deviance when mean diameter was fitted after either date or $\log$ density are $\chi^{2}=1.034$ and $0.211,1 \mathrm{df}$, respectively

\begin{tabular}{|c|c|c|c|c|c|c|}
\hline Factor & $\begin{array}{l}\text { Change in deviance } \\
\text { from null model }\end{array}$ & $\mathrm{df}$ & $\mathrm{p}$ & $\begin{array}{l}\text { Residual } \\
\text { deviance }\end{array}$ & df & $\mathrm{p}$ \\
\hline Date & 7.36 & 2 & 0.05 & 20.43 & 10 & 0.025 \\
\hline Log(density) & 8.78 & 1 & 0.005 & 19.00 & 11 & $>0.05$ \\
\hline Mean diameter & 6.31 & 1 & 0.025 & 21.48 & 11 & 0.025 \\
\hline
\end{tabular}

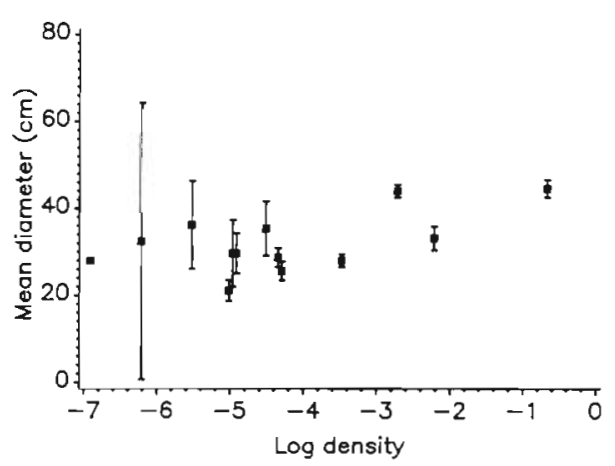

Fig. 7. Acanthaster planci. The relationship between starfish density and mean starfish diameter on the 13 transects. 95\% confidence intervals for mean starfish diameter are shown.

$$
r=0.58, p<0.05
$$

but none is capable of explaining a significant amount of variation fitted after any one of the others at $\mathrm{p}<0.05$, although log density fitted after either date or diameter is significant at approximately the 0.1 level. Mean starfish diameter fitted after either date or log density provided virtually no improvement in fit. The significant difference in injury levels between survey dates results from the high levels of injury recorded during the second survey period, when only low density areas containing small starfish were sampled. Given that few recent injuries were observed and that regeneration is slow, the observed differences in injury levels between dates are likely to be incidental results of differences in one of the other 2 factors investigated.

The preceding analysis is concerned with comparing the proportion of starfish injured between transects. It is also possible to investigate the effect of starfish size on the probability of injury within transects. On a given transect, are small starfish more or less likely than large ones to be injured? There is weak evidence that starfish diameter influences the probability of a starfish being injured within transects $\left(\chi^{2}=2.91,1 \mathrm{df}, \mathrm{p}<0.1\right)$.

\section{DISCUSSION}

These data, collected from a population of adult Acanthaster planci undergoing an outbreak, show a high rate of damage to starfish caused by predation. The identity of the predators causing these injuries is unknown. During the actual transect surveys (ca 50 diver-hours), only 2 fishes that could be regarded as potential predators were seen (one Maori wrasse Cheilinus undulatus and one coral cod Cephalopsis sp). Casual observation during other work at Holbourne Island resulted in the sighting of $6 \mathrm{C}$. undulatus (30 to $40 \mathrm{~cm}), 11$ Plectropoma spp., 3 Epinephelus spp., 3 Arothron hispidus, one school of Bolbometopon spp. and 11 Lethrinus spp. No large gastropods were seen. Compared with their populations on reefs protected as Marine Parks (e.g. Heron Island), the populations of large fish species were extremely low. The high rates of injury observed are therefore surprising. They are, however, within the broad range of 17 to $60 \%$ damage reported in 7 other surveys of sublethal predation (Moran 1986).

Our results extend previous work by showing that the proportion of injured starfish varied on a local scale within a single reef, and was lowest in areas of high starfish density. As regeneration of arms is a slow process (Owens 1971), there is no reason to suppose that starfish were at the densities at which we observed them when injuries occurred. The significant influence of starfish density on the injury frequency is best thought of as being a difference between injuries to those starfish in aggregated front populations and injuries to the more widely dispersed starfish feeding 
away from the front. Rather than attempt the potentially subjective classification of each transect into 'front' or 'non-front', we have chosen the more objective criterion of local starfish density on the transect, which also results in a single degree of freedom comparison.

The significance of this result is that it is consistent with the existence of a Type II functional response (Holling 1959) on the part of the predators. Such a functional response, in which the predation intensity per prey individual is a decreasing function of prey density, is usually attributed to predator satiation or occurs because the handling time required for the consumption of each item of prey is large. In general terms, a Type II response means that prey at high densities can escape from predation. Given the high levels of injury found in this study, which was on a population undergoing an outbreak, a Type II response suggests that the predation pressure on 'normal' low density Acanthaster planci populations may be large indeed.

Our results may also indicate that predation occurs at higher rates in small individuals, leading to the possibility of an 'escape in size' from predation. Statistically, the explanation of density is slightly favoured over that of size (Table 2), but this does not necessarily imply it is the correct biological explanation. It is quite possible that both factors are of importance in determining the probability of starfish being injured, and the significance at $p<0.1$ of density fitted after diameter and diameter within transects indicate that this may be the case.

The positive correlation between starfish density and diameter which exists in our data is interesting, but not unexpected. Most recorded aggregations of Acanthaster planci, such as the front we observed, consist of large individuals (Moran 1986). Resource limitation would not be expected to limit growth of individuals whilst at high density in a feeding front because the front moves continually onto previously unexploited coral.

McCallum $(1987,1989)$ has investigated theoretically the factors that determine the ability of a predator to control and regulate Acanthaster planci populations. The predator functional response emerges as a feature of central importance to the predator-prey interaction. If the predation rate per starfish is a decreasing function of starfish density, then polyphagous predators may be able to prevent a starfish outbreak occurring on a given reef, removing sufficient starfish with the result that the population on the reef remains low and is unable to replace itself. Predators therefore act as a 'buffer' against variability in recruitment from outside the reef or variability in starfish immigration. Theoretically, sufficiently high external recruitment or immi- gration could swamp the predators, leading to an outbreak. Although it is not known whether the buffering capacity of predation is ever exceeded at normal predator densities, any reduction in predator numbers would decrease the buffering capacity of predation and increase the likelihood of outbreaks.

If each reef is considered as a completely closed system with recruitment occurring only from within the reef (a rather unrealistic assumption), predators with a Type Ir functional response cannot alone regulate a starfish population on a given reef to a low level. In the long term, either the predators will eliminate the starfish population or there will be an outbreak. If, however, there is a limited amount of larval mixing between reefs, then such predators may be able to maintain starfish populations at low densities on most reefs (McCallum 1989).

Predators may be able to regulate the starfish population on a single reef, maintaining it at a low level, if there is a range of starfish densities over which the predation rate is an increasing function of prey density (a Type III functional response). Prey-switching behaviour of predators or preferential predation on prey aggregations are likely to lead to a Type III functional response (Murdoch \& Oaten 1975). Our results do not preclude the existence of a Type III response: most of the densities examined are above what would usually be regarded as a 'normal' starfish density (Moran 1986) and it remains possible that at lower densities predator damage is positively correlated with density.

Schoener (1979) has cast doubt on the utility of the amount of sublethal damage as an index of predation pressure on the basis that the proportion of injured individuals present in a population is determined by the proportion of attacks causing the death of the prey (the 'efficiency' of predation) and the attack rate (the 'intensity' of predation). Assuming a stable age distribution and no mortality source other than predation, he showed that the proportion of individuals without injury is dependent entirely on the efficiency of predation and is independent of predation intensity.

The assumption of a stable age distribution is most unlikely to apply to the starfish population at $\mathrm{Hol}-$ bourne Island. If a crude approximation is to be made, it would be more accurate to regard the population as a single cohort, although the size distribution of starfish is bimodal (Fig. 4) indicating the possible presence of 2 cohorts. Assuming the existence of a single cohort, the intensity and efficiency of predation are of equal importance in determining the proportion of injured individuals. Schoener also assumes age-independent attack rates from predation, together with lifelong evidence of injury. These assumptions would lead to injuries being cumulative and hence at higher frequen- 
cies in older (and therefore probably larger) individuals. Whilst the relationship between size and injury frequency is confounded in our data by density effects, if diameter alone is used as a predictor, the observed relationship between size and damage is negative, not positive, and if density effects are taken out, no clear relationship in either direction is evident.

The lack of a positive relationship between size and damage level suggests that the observed differences between transects are not related to variability in predator efficiency between transects. Presumably, large starfish would be more likely to escape with damage rather than being totally consumed, again leading to a positive relationship between diameter and frequency of injury.

It is possible that, rather than predation occurring at an age-independent rate, starfish pass through a 'window of vulnerability' at relatively small sizes, so that differences in the frequency of damage observed in different size classes merely represent the extent to which complete regeneration has had time to occur. This would indeed lead to the observed relationship between damage frequency and diameter, but the lack of a clear relationship between size and damage within transects again indicates that a difference between damage levels to starfish on the different transects is being observed, rather than simply a size-related phenomenon.

These data cannot be converted to an absolute rather than a relative index of predation pressure without a separate estimate of the total mortality rate (Schoener 1979) and an estimate of the time required until an injury is undetectable. Information on the regeneration rate of crown-of-thorns arm injuries is very limited. Owens (1971) reported an arm regeneration rate of $1 \mathrm{~cm}$ in length per $100 \mathrm{~d}$ for a $10 \mathrm{~cm}$ starfish, and thought that regeneration may never occur to the extent that injuries are undetectable.

A fundamental problem is to relate these observations of injuries to possible increases in starfish mortality. Even substantial predator damage does not necessarily lead to death (Owens 1971). There are several ways, however, by which attacks may lead to increased mortality. First, the individuals we detect with missing arms may be the survivors of unsuccessful attacks by predators that usually completely destroy the starfish. Second, some predators attack recently mutilated starfish at far higher rates than they do intact specimens. For example, Glynn (1984) reported attack rates of 0.9 starfish $^{-1} \mathrm{~d}^{-1}$ by the polychaete Pherecardia striata on tethered individuals with one arm removed, whereas he did not observe any attacks on undamaged starfish similarly tethered. Third, there is some evidence (Lucas 1984, Zann et al. 1987) that pathogenic infections may have significant effects on starfish populations. These are likely to be better able to infect individuals with damage to their integument than intact specimens.

Although it may be appropriate to view a sublethal predator attack as 'unsuccessful' (Vermeij 1982) when considering tail loss of lizards or drill holes on molluscs, this may not be appropriate when considering damage to the crown-of-thorns starfish. Predators may well be satiated after consumption of 1 or 2 Acanthaster planci arms, and a sublethal attack cannot therefore be regarded as 'unsuccessful' or 'inefficient'. Incomplete consumption of prey may have effects on prey population dynamics independent of any increase in mortality. Any removal of biomass is a loss of production and may lead to lowered reproductive output either because portions of the gonads are directly removed or because energy is diverted from reproduction to regeneration or somatic growth. Evidence of this is firmly established in plants suffering grazing (Crawley 1983 , p. 52, Harper 1977, p. 442). The extent to which arm loss may be related to decreases in fecundity in $A$. planci has yet to be established.

Acknowledgements. We thank Ken Day, Alistair Melzer, Robyn Cumming and Lyndon DeVantier for work in the field. Funding was provided by the Great Barrier Reef Marine Park Authority, and administered through Uniquest, University of Queensland.

\section{LITERATURE CITED}

Crawley, M. J. (1983). Herbivory. Blackwell, Oxford

Crown Of Thorns Starfish Advisory Committee (1985). Report to Great Barrier Reef Marine Park Authority, PO Box 1379, Townsville, 4810 Australia

Endean, R. (1969). Report on investigations made into aspects of the current Acanthaster planci (crown-of-thorns) infestations of certain reefs of the Great Barrier Reef. Fisheries Branch, Queensland Department of Primary Industries, Brisbane

Endean, R. (1973). Acanthaster planci population explosions. In: Jones, O.A., Endean, R. (eds.) Biology and geology of coral reefs, Vol. II, Biology 1. Academic Press, New York, p. $389-438$

Endean, R., Cameron, A. M. (1985). Ecocatastrophe on the Great Barrier Reef. Proc. 5th. Intl. Coral Reef Congr., Vol. 5: 309-314

Endean, R. Cameron, A. M. (in press). Acanthaster planci population outbreaks. In: Dubinsky, Z. (ed.) Ecosystems of the world, Vol. 25, Coral reefs. Elsevier, Amsterdam.

Glynn, P. W. (1984). An amphinomid worm predator of the crown-of-thorns sea star and general predation of asteroids in eastern and western Pacific coral reefs. Bull. mar. Sci. 35: $54-71$

Harper, J. L. (1977). Population biology of plants. Academic Press, London

Holling. C. S. (1959). The components of predation as revealed by a study of small mammal predation of the European pine sawfly. Can. Ent. 91: 293-320

Lucas, J. S. (1984). Growth, maturation and effects of diet in 
Acanthaster planci (L.) (Asteroidea) and hybrids reared in the laboratory. J. exp. mar. Biol. Ecol. 79: 129-147

McCallum, H. I. (1987). Predator regulation of Acanthaster planci. J. theor. Biol. 127: 207-220

McCallum, H. I. (1989). Effects of predation on organisms with pelagic larval stages. Proc. Sixth Intl. Coral Reef Symp. (in press)

McCullagh, P., Nelder, J. A. (1983). Generalized linear models. Chapman and Hall, London

Moran, P. J. (1986) The Acanthaster phenomenon. Oceanogr mar. biol. A. Rev. 24: 379-480

Murdoch, W. W., Oaten, A. (1975). Predation and population stability. Adv. ecol. Res. 9: 1-131

Owens, D. (1971). Acanthaster planci starfish in Fiji: survey of incidence and biological studies. Fiji Agric. J. 33: 15-23

Paine, R. T. (1966). Food web complexity and species diversity. Am. Nat. 100: 65-75

Potts, D. C. (1982). Crown-of-thorns starfish - man-induced pest or natural phenomenon? In: Kitching, R. L., Jones,

This article was submitted to the editor
R. E. (eds.) The ecology of pests. CSIRO, Melbourne, p. $55-86$

Schoener, T. W. (1979). Inferring the properties of injuryproducing agents from injury frequencies. Ecology 66: $1110-1115$

Sides, E. M. (1987). An experimental study of the use of arm regeneration in estimating rates of sublethal injury on brittle stars. J. exp. mar. Biol. Ecol. 106: 1-16

Vermeij, G. J. (1982). Unsuccessful predation and evolution. Am. Nat. 120: 701-720

Yamaguchi, M. (1973). Early life histories of coral reef asteroids, with special reference to Acanthaster planci (L.). In: Jones, O. A., Endean, R. (eds.) Biology and geology of coral reefs, Vol. II, Biology 1. Academic Press, New York, p. $369-387$

Zann, L., Brodie, J., Berryman, C., Naqasima, M. (1987). Recruitment, ecology, growth and behavior of juvenile Acanthaster planci L.) (Echinodermata: Asteroidea). Bull. mar. Sci. 41. 561-575

Manuscript first received: October 10,1988

Revised version accepted: May 10, 1989 